\title{
A Comparison of the Environmental Performance of Cooling and Heating among Different Household Types in China's Hot Summer-Cold Winter Zone
}

\author{
Shu Su ${ }^{1,2, * \mathbb{C}}$, Xiaodong $\mathrm{Li}^{3}$, Borong Lin ${ }^{4}$, Hongyang $\mathrm{Li}^{5}$ and Jingfeng Yuan ${ }^{1}$ \\ 1 Department of Construction and Real Estate, School of Civil Engineering, Southeast University, \\ Nanjing 211189, China; jingfeng-yuan@seu.edu.cn \\ 2 Engineering Research Center of Building Equipment, Energy, and Environment, Ministry of Education, \\ Nanjing 210096, China \\ 3 Department of Construction Management, School of Civil Engineering, Tsinghua University, \\ Beijing 100084, China; eastdawn@tsinghua.edu.cn \\ 4 Department of Building Science, School of Architecture, Tsinghua University, Beijing 100084, China; \\ linbr@tsinghua.edu.cn \\ 5 School of Civil Engineering and Transportation, South China University of Technology, \\ Guangzhou 510641, China; cthyli@scut.edu.cn \\ * Correspondence: sushu@seu.edu.cn
}

Received: 28 August 2019; Accepted: 11 October 2019; Published: 16 October 2019

\begin{abstract}
Cooling and heating consume a large amount of energy during the operation of residential buildings in the hot summer-cold winter zone. It causes serious ecological damage and negatively affects natural resources. Occupant usage behaviors of cooling and heating systems are driven by various factors, and correlations between the driving factors and corresponding environmental impacts (EIs) are not well quantified. This study focuses on two occupant-related driving factors: household size and age composition, and combines a questionnaire survey, an energy simulation, and an EIs assessment into an integrated model. A case study is conducted in Jiangsu, China, to demonstrate the model. Nearly 1800 samples are collected from a large sample questionnaire survey and then classified into nine household types according to their household sizes and age compositions. The EIs due to cooling and heating of different household types in a typical year are then assessed and compared. The assessment results show that different household types have various environmental performance. Households with larger size, elderly people, and children have higher EIs. This newly established model is applicable and builds a bridge between driving factors and the environmental performance of cooling and heating. These assessment results will help better understand the role of household type.
\end{abstract}

Keywords: cooling and heating; environmental impact assessment; household type; occupant behaviors; hot summer-cold winter zone

\section{Introduction}

In residential buildings, cooling and heating result in considerable environmental impacts (EIs), in both developed countries [1] and developing countries [2]. It is widely believed that EIs due to cooling and heating will continue to increase in the future, and this topic is worthy of more attention [3,4]. During the cooling and heating, occupant behavior plays a significant role [5-8]. Proper occupants' interactions with building systems could make green designs work better $[9,10]$. A research showed that the cooling energy consumption of different households in a same building, which were all 
equipped with split air conditioners, varied by orders of magnitude [11]. The critical role of occupant behaviors was recognized, and this aspect has attracted more attention recently [6,12-14].

Cooling and heating as well as the related occupant behaviors in the hot summer-cold winter climate zone in China deserve special attention. The hot summer-cold winter climate zone covers almost half of the provinces in China with dense population and fast-growing economy. The weather is sultry in summer and cold and wet in winter. Space cooling and heating in this region is a major domestic energy consumer and pollutant emitter [2], playing an important role in China's building energy conservation task [15]. According to the Chinese heating policy, no district heating is provided in this region. Individual facilities, especially air conditioners, are widely installed and utilized for heating. Thus, air conditioners in this region are often used for both cooling and heating [16], and occupant behavior plays a significant role during the usage.

Turning on, turning off, and temperature setting are three typical air-conditioner usage behaviors, and they are affected by various driving factors, including climate factors (e.g., outdoor temperature and humidity) $[17,18]$, building and system factors (e.g., building type, building age, air-conditioning system and heating system) [19-21], and occupant related factors (e.g., age, gender, and income) [22,23]. Among the three types of driving factors, climate factors and building and system factors are less subjective than the occupant-related ones, which are complex and significant [24]. This study investigates occupant related driving factors, and focuses on occupant age and household size, which have close correlations with usage behaviors [7]. The proportion of elderly people in China is predicted to increase by nearly $20 \%$ before 2050 [25], and more children will be born due to the recent two-child policy. Thus, occupant age and its role in energy use deserve more attention.

Various studies have been conducted regarding the roles of occupant age and household size in cooling and heating. Oreszczyn et al. [26] conducted a survey in UK and found that temperatures in dwellings were influenced by many characteristics, including the household number of people and the age of the head of household. Sardianou [27] estimated the space heating determinants among Greek households using several regression techniques and showed that the age of respondent and family size are suitable to explain the differences. Other research in China also adopted regression analysis and showed similar conclusions [28]. Some studies just focused on the elderly's energy demands and found they relied more heavily on space heating and required warmer temperatures in winter $[29,30]$.

However, current studies still have some limitations. First, most of these studies used energy consumption as the evaluation indicator, but this is, in fact, not a good indicator. Energy consumption fails to represent the real damage to environment. In addition, it does not support comparisons across geographical areas because in different regions the fuel structures, input raw material qualities, involved technologies, and labors of unit energy vary [31]. Taking the carbon footprint of $1 \mathrm{kWh}$ of Chinese grid power on the provincial level in 2014 as an example, the highest value was nearly six times the lowest one [32]. Thus, the same amount energy consumption in different regions may not bring equal environmental damages for they may consume different raw materials and discharge various amounts of emissions. Impact indicators are much better alternatives. Second, scholars often surveyed households in many buildings and even in different areas to collect research data [24,29]. This means that the influences of the other two types of objective driving factors (climate factors and building and system factors) cannot be totally excluded, and this inevitably causes uncertainties to the results. Controlling these objective driving factors and focusing on the influences of occupant age and household size could be better. Finally, the involved samples are limited, such as a few hundred respondents from questionnaires [22,29] or dozens of cases from field surveys [33]. The samples are often classified into a few rough categories (e.g., just according to household size or age composition), for the small numbers do not support sophisticated classifications. In the consideration of both household size and age composition, larger samples are required to support further detailed household types.

To overcome these shortfalls, this study adopts EI indicators to replace the traditional energy use indicator. Samples are classified into more detailed household types and an integrated model is developed to quantify the influences of age composition and household size with the other two types of 
driving factors controlled. The study is organized as follows. Section 2 introduces the methodology that includes the integrated assessment model, evaluation steps, and methods involved. Section 3 presents a study in Jiangsu Province to demonstrate the developed assessment framework. Section 4 compared the cooling and heating related environmental performance of nine household types. The influences of household size and age composition are also analyzed. Section 5 discusses the main contributions and limitations of this study. Finally, conclusions are drawn.

\section{Methodology}

\subsection{An Integrated Assessment Framework}

This research combines a questionnaire survey, an energy simulation, and an EI assessment together to develop an integrated model. The model is shown in Figure 1 and has three steps.

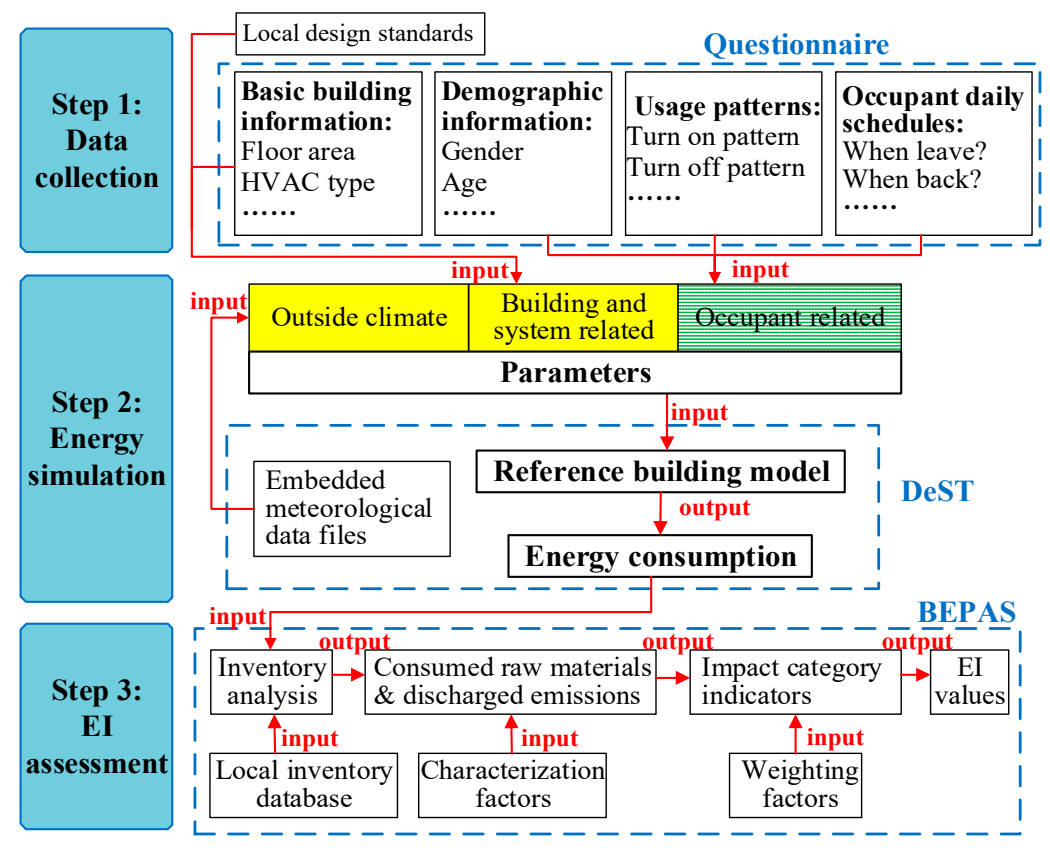

Figure 1. Framework of the integrated assessment model.

- Data collection. The first step prepares the required parameter data for the following simulation by a large sample questionnaire survey. Four types of data are needed. The basic building information is collected to support the development of a reference building model for the simulation. Typically, the average values and/or most common values of the samples are adopted. Demographic information of the household members, air-conditioner usage patterns, and daily schedules are the foundation for setting the occupant related parameters for the simulation.

- Energy simulation. This study uses simulation to obtain energy use data rather than referring to statistics [34,35] or conducting field monitoring [36,37]. An important advantage of simulation is that the other two types of driving factors can be controlled at fixed levels under various scenarios of occupant information and behaviors. Among the input parameters, climate data and building- and system-related data (as highlighted in yellow in Figure 1) are set as constant values during the whole simulation. The occupant-related data (as highlighted in green in Figure 1) are sample-specific. In this way, it is possible to just quantify the influences of occupant-related driving factors and exclude other factors' influences. In addition, simulation is an effective and widely-used method to calculate energy levels and to guide designs [38,39]. In this integrated model, Designer's Simulation Toolkit (DeST) [40] is recommended to conduct the simulation. Detailed introductions are provided in Section 2.3. 
- Environmental impact assessment. The final step transforms the simulated energy consumption into damage indicator values using an EI assessment model. The Building Environmental Performance Analysis System (BEPAS) [41] is suggested to conduct the inventory analysis, characterization and weighting. Evaluators can choose other mature EI assessment models, such as Athena [42], Envest [43] and Building for Environmental and Economic Sustainability (BEES) [44], to complete this step according to their research goals and preferences.

\subsection{Questionnaire Survey}

The questionnaire survey is a major method used to collect necessary input data for simulation. According to the research goal and operation requirements of DeST, a questionnaire is designed containing four parts of information: basic building information, demographic information, occupant daily schedules, and air conditioner usage patterns, as shown in Table 1.

Table 1. Information in the questionnaire.

\begin{tabular}{cc}
\hline Part & Investigated Data \\
\hline Basic building information & Floor area, building age, etc. \\
\hline Demographic information & $\begin{array}{r}\text { Family member number, number of unemployed elderly people, } \\
\text { number of children younger than 15 years old, household income, } \\
\text { age and gender of the household's head, etc. }\end{array}$ \\
\hline Occupant daily schedules & $\begin{array}{r}\text { Uninhabited days, occupancy time (hours in a day) on weekdays and } \\
\text { weekends, etc. }\end{array}$ \\
\hline Usage patterns of air conditioner & $\begin{array}{c}\text { Power of the air conditioner, turn on pattern in summer, turn off pattern } \\
\text { in summer, temperature setting in summer, turn on pattern in winter, } \\
\text { turn off pattern in winter, temperature setting in winter, etc. }\end{array}$ \\
\hline
\end{tabular}

The basic building information portion includes questions about the floor area, building type, building age, and others. These investigated results assist in understanding the characteristics of surveyed residential buildings. They also provide a basis for developing the reference building model for the simulation.

Demographic information primarily consists of household size and age composition data. The surveyed samples are classified into some different household types according to their household sizes and age compositions. Referring to the existing literature [16], three age groups are considered (i.e., unemployed elderly people, children younger than 15 years old, and adults) for their different occupancy schedules and cooling and heating demands. Besides, the household income, age and gender of the household's head, and other information are also surveyed.

The occupant daily schedules describe when the house is occupied, which are important because occupancy is the premise of cooling and heating. Schedules on weekdays and weekends are generally different, and these two schedules are described separately. In addition, considering that modern families like to travel on vacations and may go back to hometowns during festivals, the questionnaire also investigates the number of uninhabited days.

Cooling and heating usage patterns are important parameters, and the cooling behaviors and heating behaviors are investigated separately. Five typical turn on patterns and five turn off patterns are included in the survey to be in line with the embedded behavior module in DeST $[45,46]$. The turn on patterns include never, always, when entering the room, when feeling hot/cold, and before sleeping. The turn off patterns include never, when leaving the room, before sleeping, after getting up, and when feeling cold/hot.

\subsection{Energy Simulation}

This study uses the DeST to conduct an energy simulation. DeST has been widely adopted to simulate and analyze building energy consumption and heating, ventilation, and air conditioning 
(HVAC) systems in China, Japan, and some European countries with thousands of users [47]. Variable and stochastic occupant behaviors are also considered in DeST, and this makes its application results better reflect the reality [45]. An occupant behavior module is embedded by using conditional probability functions based on the concept of Markov transfer matrix, and it involves human behaviors related to environmental triggers, event triggers and random triggers [45]. Operators can directly employ the occupant behavior module in the software, which is very convenient and user-friendly.

Seven specified versions of DeST have been developed to better meet the corresponding application areas, such as DeST-s for solar building simulations and DeST-c for commercial building simulations. This study adopts the DeST-h version, which considers the specific characteristics of residential buildings and residents. According to the manual of DeST-h [48], the major simulation steps are summarized as reference building development, parameters setting and analog computation.

- Reference building development. First, a building model is developed in the software interface according to the architectural characteristics and parameters from surveyed samples as well as local standards.

- Parameters setting. The necessary parameters are set to support the energy simulation, including the outdoor climate parameters (the embedded weather data file in the DeST-h is used directly), building- and system-related parameters (location, orientation, component parameters, HVAC system, etc.), and occupant-related parameters (occupant schedule, turn-on and turn-off patterns of devices, probability functions of behaviors, etc.).

- Analog computation. Executing the commands to simulate the room temperature in a year and then output the related energy consumptions.

\subsection{Environmental Impact Assessment}

BEPAS investigates a building's EIs and then allocates them into two areas of protection (ecological environment and natural resource). BEPAS follows the well-known life cycle assessment paradigm and provides comprehensive quantitative results that can potentially facilitate decision-makings. These aspects have great advantages over qualitative scoring approaches, such as the Assessment Standards for Green Buildings [49] and the Evaluation Standards for the Green Construction of Buildings [50].

Specialized for buildings, BEPAS is a mature model with wide applications in guiding design [51], promoting environmental policy implementation [52,53], and quantifying EIs of various buildings, components and materials (such as prefabricated buildings [54], residential buildings [55], concrete columns [56], concrete slabs [57], and cement [55]). The BEPAS model contains four basic assessment steps: goal and scope definition, inventory analysis, impact assessment, and interpretation $[41,58]$.

- Goal and scope definition. First, the intended application and reasons for conducting an assessment should be clearly stated, and the specific system boundary, functional unit, and level of detail need to be defined.

- Inventory analysis. This step transforms energy consumption data into inputs (the raw materials and primary energy required to realize functions) and outputs (consequent pollutant emissions to the air, water, soil and other environmental media). The use of region-specific inventory datasets of energy is significant in this step. The Chinese Life Cycle Database (CLCD) is recommended to support the inventory analysis. CLCD could provide different inventory datasets of energy in various regions of China considering the various power mix levels and power transmissions [32].

- Impact assessment. To understand and evaluate the magnitude and significance of potential EIs, classification, characterization and weighting are conducted in this step. The BEPAS model assigns different inputs and outputs to some ecological damage categories and resource-depletion categories, and then quantifies their potential impacts using characterization factors. The relative severity levels across different impact categories are then weighted using weighting factors, which 
are established by using the social willingness to pay approach. Finally, the EI values of different impact categories are all expressed in a unified monetary unit with economic meanings.

- Interpretation. This step analyzes the final results, reaches conclusions, explains limitations, and provides recommendations based on the findings.

\section{A Study in Jiangsu Province}

A case study was conducted using urban households living in the Jiangsu Province in China as samples. Jiangsu is located at the eastern coastal area in the hot summer-cold winter climate zone and is a typical province with rapid economic development and rapid urbanization.

\subsection{Data Collection}

A large sample questionnaire survey of urban households in Jiangsu Province was conducted online from May to July in 2017 by cooperating with a professional questionnaire survey company (The questionnaire is added as the Supplementary Materials). The company selected potential respondents for this survey according to the research demands from its respondent pool, and then sent them questionnaires online randomly. The collected samples were checked carefully by the company and authors independently. Finally, 1747 valid samples regarding air-conditioner usage for cooling in summer were collected, and the total amount of the valid responses for heating in winter was 1151. The process of questionnaire survey is shown in Figure 2. The samples were classified into nine household types according to their household sizes and age compositions, as shown in Table 2. Nearly $85 \%$ of the households in Jiangsu are composed of two to five persons [59], so samples of households with only one person and those with more than five persons were dropped from the study. The studied household sizes consisted of two, three, four, and five persons. Furthermore, according to whether there were old persons or children among the family members, households with three and four persons were further divided into many types: IIIOC, IIIAO, IIIAC, IIIA, IVAC, IVAO, and IVACO. The "IVA" type was deleted for its small possibility. In addition, there were only two family members with type "II", so corresponding samples were not further divided. Among the five-person households, only "VACO" was considered. The other types were excluded because most five person families were composed of adults, children, and old persons.

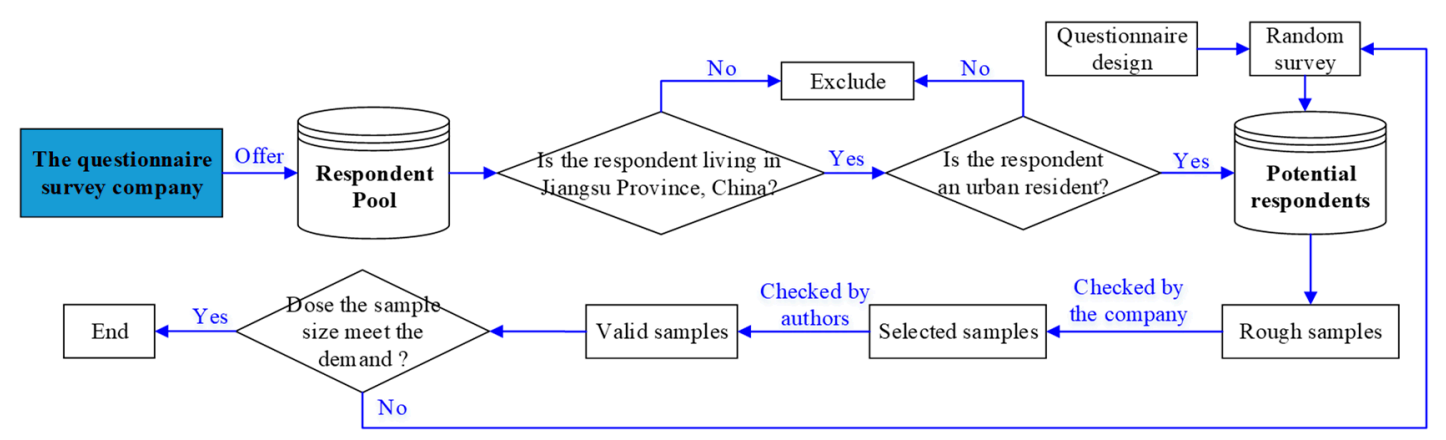

Figure 2. The process of questionnaire survey.

Five typical turn-on patterns and five turn-off patterns of air conditioner usage were defined in the questionnaire. The usage patterns and their codes are listed in Table 3, and there are at most 25 combination usage patterns. According to the survey results, Figure 3 shows the proportions of each combination pattern of the nine household types. It can be seen that (1) different household types had various usage habits. Even for the same household type, different families may have different choices; (2) most households in Jiangsu controlled the air conditioners depending on their thermal perceptions. Thus "turn on when feeling hot and turn off when feeling cold in summer" (De) and "turn on when feeling cold and turn off when feeling hot in winter" (Ij) shared the highest proportions, approximately $40 \%$ and $30 \%$ respectively. In addition, "entering room" and "leaving room" were 
two common triggers of turning on and turning off the air conditioners; and (3) there were also a few surveyed households (approximately $7 \%$ ) insisting on not using air conditioners for heating in winter, even though they owned the equipment.

Table 2. The classification of household types.

\begin{tabular}{|c|c|c|c|c|c|c|}
\hline \multirow{2}{*}{$\begin{array}{c}\text { Household } \\
\text { Type }\end{array}$} & \multirow{2}{*}{$\begin{array}{l}\text { Household } \\
\text { Size }\end{array}$} & \multicolumn{3}{|c|}{ Age Composition } & \multicolumn{2}{|c|}{ Proportion of Samples } \\
\hline & & Adults & Old Persons & Children & $\begin{array}{l}\text { Cooling in } \\
\text { Summer }\end{array}$ & $\begin{array}{c}\text { Heating in } \\
\text { Winter }\end{array}$ \\
\hline II & 2 & - & - & - & $7.56 \%$ & $10.51 \%$ \\
\hline IIIOC & & $x$ & $\sqrt{ }$ & $\sqrt{ }$ & & \\
\hline IIIAO & 3 & $\sqrt{ }$ & $\sqrt{ }$ & $x$ & $5031 \%$ & $4839 \%$ \\
\hline IIIAC & 3 & $\sqrt{ }$ & $x$ & $\sqrt{ }$ & $50.31 \%$ & $48.39 \%$ \\
\hline IIIA & & $\sqrt{ }$ & $x$ & $x$ & & \\
\hline IVAC & & $\sqrt{ }$ & $x$ & $\sqrt{ }$ & & \\
\hline IVAO & 4 & $\sqrt{ }$ & $\sqrt{ }$ & $x$ & $22.78 \%$ & $21.29 \%$ \\
\hline IVACO & & $\sqrt{ }$ & $\sqrt{ }$ & $\sqrt{ }$ & & \\
\hline VACO & 5 & $\sqrt{ }$ & $\sqrt{ }$ & $\sqrt{ }$ & $19.35 \%$ & $19.81 \%$ \\
\hline
\end{tabular}

Note: $\mathrm{II}=2$ persons, $\mathrm{III}=3$ persons, $\mathrm{IV}=4$ persons and $\mathrm{V}=5$ persons. $\mathrm{A}=$ adults, $\mathrm{O}=$ old persons, and $\mathrm{C}=$ children.

Table 3. Typical patterns and codes for turning air conditioners on and off.

\begin{tabular}{|c|c|c|c|c|c|c|c|}
\hline \multicolumn{4}{|c|}{ For Cooling in Summer } & \multicolumn{4}{|c|}{ For Heating in Winter } \\
\hline never & $\mathrm{A}$ & never & $\mathrm{a}$ & never & $\mathrm{F}$ & never & $\mathrm{f}$ \\
\hline when entering the room & $\mathrm{C}$ & before sleeping & c & when entering the room & $\mathrm{H}$ & before sleeping & $\mathrm{h}$ \\
\hline when feeling hot & $\mathrm{D}$ & after getting up & $\mathrm{d}$ & when feeling cold & I & after getting up & $\mathrm{i}$ \\
\hline before sleeping & $\mathrm{E}$ & when feeling cold & $\mathrm{e}$ & before sleeping & $\mathrm{J}$ & when feeling hot & j \\
\hline
\end{tabular}

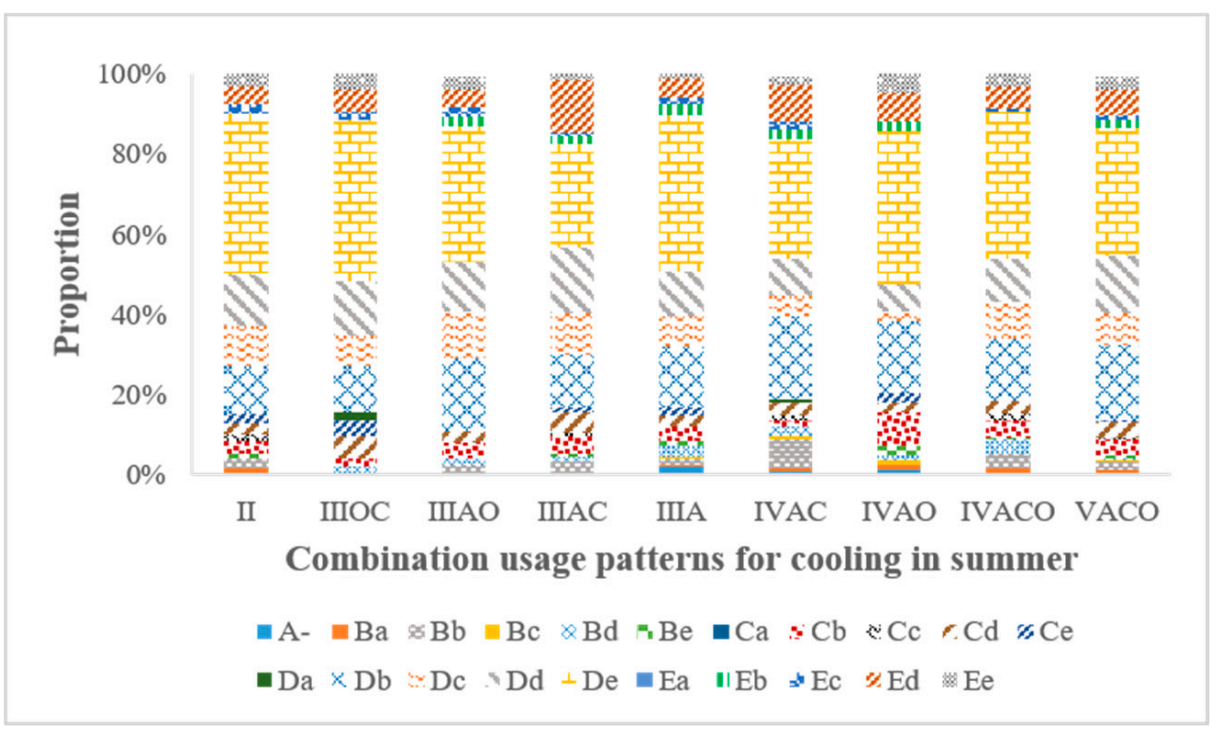

(a)

Figure 3. Cont. 


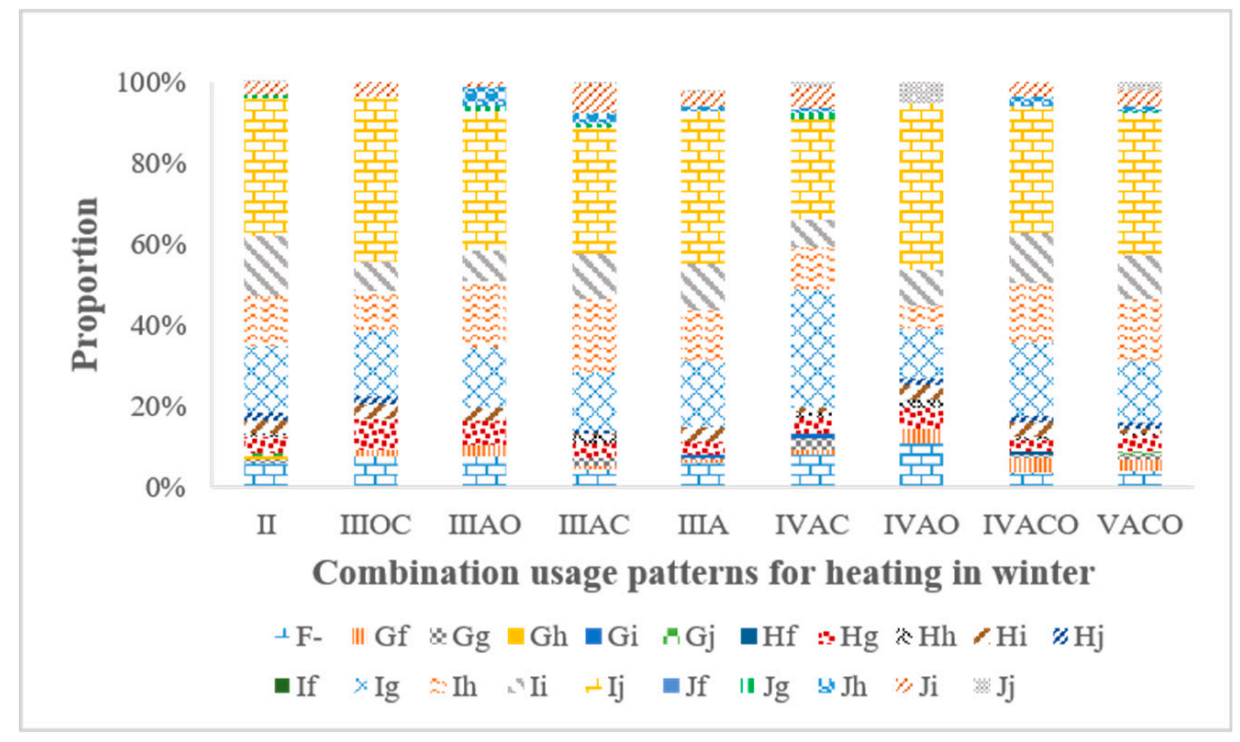

(b)

Figure 3. The proportions of combination usage patterns for air conditioners (a) in the summer and (b) in the winter of nine household types. Note: $\mathrm{Aa}, \mathrm{Ab}, \mathrm{Ac}, \mathrm{Ad}$, and Ae patterns are all written as "A-" in the figure; Ff, Fg, Fh, Fi, and Fj patterns are all written as "F-" in the figure.

\subsection{Energy Simulation}

After the collection of parameter data, this step uses DeST-h to simulate the related energy consumption. The reference residential building model is shown in Figure 4, and the floor area of each household was set to be $132 \mathrm{~m}^{2}$ according to the average value of the samples. Some envelope properties were set according to the Design Standard of Thermo-Environment and Conservation for Residential Buildings in Jiangsu Province [60], as shown in Table 4. The window-wall ratios of the reference building were listed in Table 5.

The embedded meteorological data files [48], which were calculated based on history data, were used in the simulation directly. The various occupant schedules and combination usage patterns from the investigation results were used as inputs. Considering the randomness of behaviors, we adopted probability functions in the simulation. The related parameters were set according to literatures $[12,46]$. The energy usage on weekdays and weekends were simulated separately, and the uninhabited days were excluded in the calculation. Finally, the energy consumption of different household types in the reference building were calculated, and the energy consumption data of one household on a middle floor was adopted as the typical example in the following assessment and analysis.

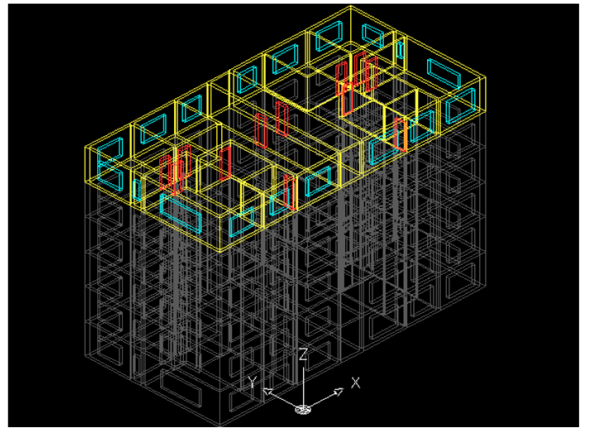

(a)

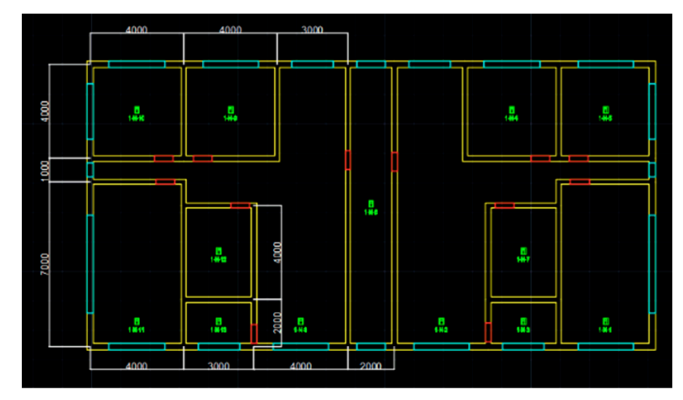

(b)

Figure 4. (a) Three-dimensional view and (b) top view of the reference residential building model. 
Table 4. Physical properties and configuration of the building envelope and interior elements [60].

\begin{tabular}{cccc}
\hline $\begin{array}{c}\text { Envelope and } \\
\text { Interior Elements }\end{array}$ & Components and Materials & $\begin{array}{c}\text { Heat Transfer } \\
\text { Coefficient }\left(\mathbf{W} \cdot \mathbf{m}^{-2} \cdot \mathbf{K}^{-\mathbf{1}}\right)\end{array}$ & $\begin{array}{c}\text { Thermal } \\
\text { Inertness Index }\end{array}$ \\
\hline External wall & $\begin{array}{c}\text { Reinforced concrete }(230 \mathrm{~mm})+\text { expanded } \\
\text { polystyrene (EPS) panel }(32 \mathrm{~mm})\end{array}$ & 1.015 & 2.533 \\
\hline Interior wall & $\begin{array}{c}\text { Reinforced concrete }(120 \mathrm{~mm})+\text { EPS panel } \\
(15 \mathrm{~mm})\end{array}$ & 1.6 & 2.307 \\
\hline Roof & $\begin{array}{c}\text { Reinforced concrete }(200 \mathrm{~mm})+\text { EPS panel } \\
(28 \mathrm{~mm})\end{array}$ & 1.149 & 1.391 \\
\hline Floor & $\begin{array}{c}\text { Reinforced concrete }(120 \mathrm{~mm})+\text { extruded } \\
\text { polystyrene board }(20 \mathrm{~mm})\end{array}$ & 1.105 & $/$ \\
\hline Door & Fiberboard without cement $(25 \mathrm{~mm})$ & $/$ & 2.2 \\
\hline
\end{tabular}

Table 5. The window-wall ratios of the reference building [60].

\begin{tabular}{cc}
\hline Orientation & Window-Wall Ratio \\
\hline South & 0.35 \\
North & 0.25 \\
East/West & 0.15 \\
\hline
\end{tabular}

\subsection{Environmental Performance Assessment}

The assessment object is the cooling and heating of nine household types, and the functional unit is one household living on the middle floor of the reference residential building in Jiangsu, China. The evaluation period spans one year from 1 December in 2016 to 30 November in 2017.

The simulated energy consumption was analyzed into inputs and outputs by the inventory dataset of energy from CLCD [61]. Characterization factors in the BEPAS model were directly used to quantify the relative contributions of each input-output to its assigned impact categories. Five ecological damage categories (global warming, acidification, eutrophication, airborne suspended particles and photochemical smog) and five resource-depletion categories (primary energy depletion, water resource depletion, timber depletion, iron resource depletion and manganese resource depletion) were involved in this study. Weighting factors from Cao et al. [54], which were calculated based on Chinese green taxes, were adopted to evaluate the relative severities of different impact categories and then summarize them into a single value in the unit of U.S. dollar. The following section analyzes the assessment results and the roles of household size and age composition with average EI values.

\section{Results and Analysis}

\subsection{Environmental Impact (EI) Values of Different Household Types}

Figure 5 summarizes the average EI values due to cooling and heating of nine household types and shows that: (1) the cooling and heating related environmental performances of the nine household types were quite different, and the highest values in summer and in winter (\$7.80 U.S. and \$7.36 U.S.) were approximately 50\% and 30\% larger than the lowest ones (\$5.09 U.S. and \$5.69 U.S.), respectively. Different household types had various EI levels when other types of driving factors were kept the same. (2) The EIs due to cooling and those due to heating were quite close. The largest difference (\$0.78 U.S.) was found for the IIIAO type, while the smallest difference (\$0.14 U.S.) was found for the IIIOC type. (3) As far as the total EIs during the entire year were concerned, the top three households with high values were VACO, IVACO, and IVAC, and the three households with the lowest values were II, IIIA and IIIAO. 


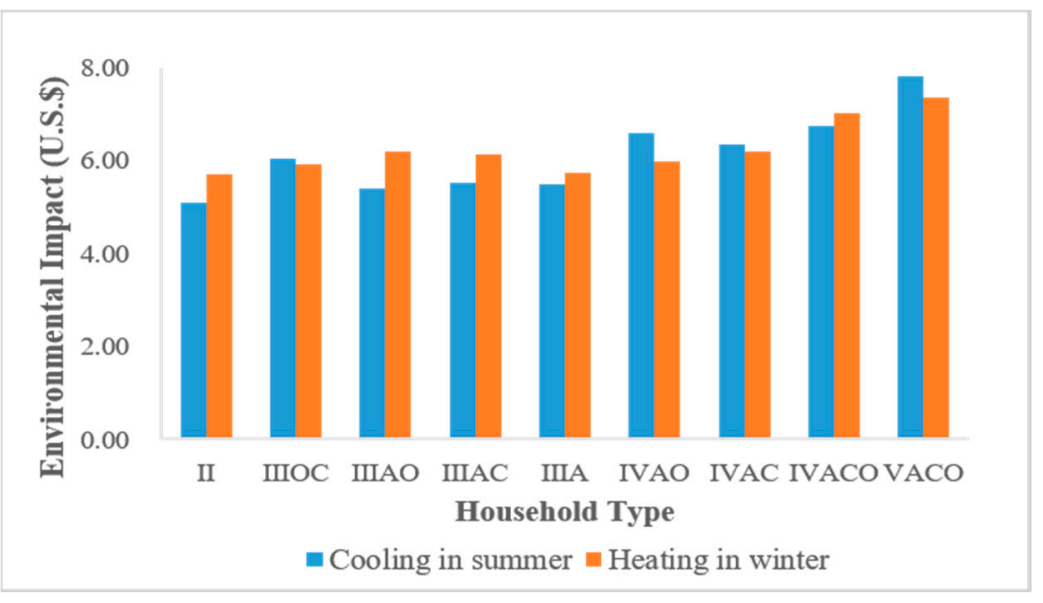

Figure 5. TheEI values due to cooling and heating of the nine household types.

\subsection{EI Values of Different Impact Categories}

The average values of all surveyed samples in the whole year were calculated, and Table 6 summarizes the category indicators, EI values of various impact categories and their shares in the total EIs. (1) The cooling and heating made a greater contribution to ecological damage than to resource depletion, and the EIs of the ecological damage categories shared nearly $85 \%$ of the total impacts. (2) The global warming impact had an absolute lead with a very large proportion, $76 \%$. A possible reason might be that $\mathrm{CO}_{2}$ composes a very large proportion of discharged emissions of per unit energy. (3) As far as the resource depletion categories, cooling and heating primarily threatened the future availabilities of primary energy and water resource. (4) The shares of photochemical smog, timber, iron and manganese were very small and nearly zero.

Table 6. The average EI values and shares of different impact categories (whole year).

\begin{tabular}{|c|c|c|c|}
\hline Category & $\begin{array}{l}\text { Impact Category } \\
\text { Indicator }\end{array}$ & EI Value (U.S.\$) & Share in Total EIs \\
\hline \multicolumn{4}{|c|}{ Ecological Damage Impacts } \\
\hline Global warming & $1.24 \times 10^{3} \mathrm{~kg} \mathrm{CO}_{2}-\mathrm{e}$ & 9.52 & $76.05 \%$ \\
\hline Acidification & $6.68 \mathrm{~kg} \mathrm{SO} 2-\mathrm{e}$ & $6.21 \times 10^{-1}$ & $4.96 \%$ \\
\hline Eutrophication & $4.69 \mathrm{~kg} \mathrm{NO}_{3}^{-}-\mathrm{e}$ & $5.06 \times 10^{-1}$ & $4.04 \%$ \\
\hline Airborne suspended particles & $1.27 \mathrm{~kg}$ & $4.14 \times 10^{-2}$ & $0.33 \%$ \\
\hline Photochemical smog & $6.35 \times 10^{-3} \mathrm{kgC}_{2} \mathrm{H}_{4}$-e & $2.57 \times 10^{-3}$ & $0.02 \%$ \\
\hline \multicolumn{4}{|c|}{ Resource Depletion Impacts } \\
\hline Primary energy depletion & $7.51 \times 10^{2} \mathrm{kgce}$ & $9.01 \times 10^{-1}$ & $7.20 \%$ \\
\hline Water depletion & $4.25 \mathrm{~m}^{3}$ & $9.05 \times 10^{-1}$ & $7.22 \%$ \\
\hline Timber depletion & $1.45 \times 10^{-3} \mathrm{~m}^{3}$ & $2.10 \times 10^{-2}$ & $0.17 \%$ \\
\hline Iron depletion & $2.60 \times 10^{-1} \mathrm{~kg}$ & $6.57 \times 10^{-4}$ & $0.01 \%$ \\
\hline Manganese depletion & $2.36 \times 10^{-5} \mathrm{~kg}$ & $6.97 \times 10^{-9}$ & $0.00 \%$ \\
\hline
\end{tabular}

\subsection{Monthly EI Values}

To clearly show the changes in EIs during an entire year, the IIIAC type was chosen as an example for it's the most common type in Jiangsu [59]. Figure 6 showed the monthly EIs of IIIAC type. The average temperature in each month from statistical materials [59] were also presented to show the weather's influence on EIs. In winter, the lower the temperature, the higher the EI; and the opposite results can be observed in summer. Besides, larger EIs were found in January for heating and in July for cooling. The air conditioner usage in each of these two months contributed approximately $22 \%$ to the total EIs in the entire year. The smallest EI was found in June, which primarily because only half of the days in this month are in the cooling period. 


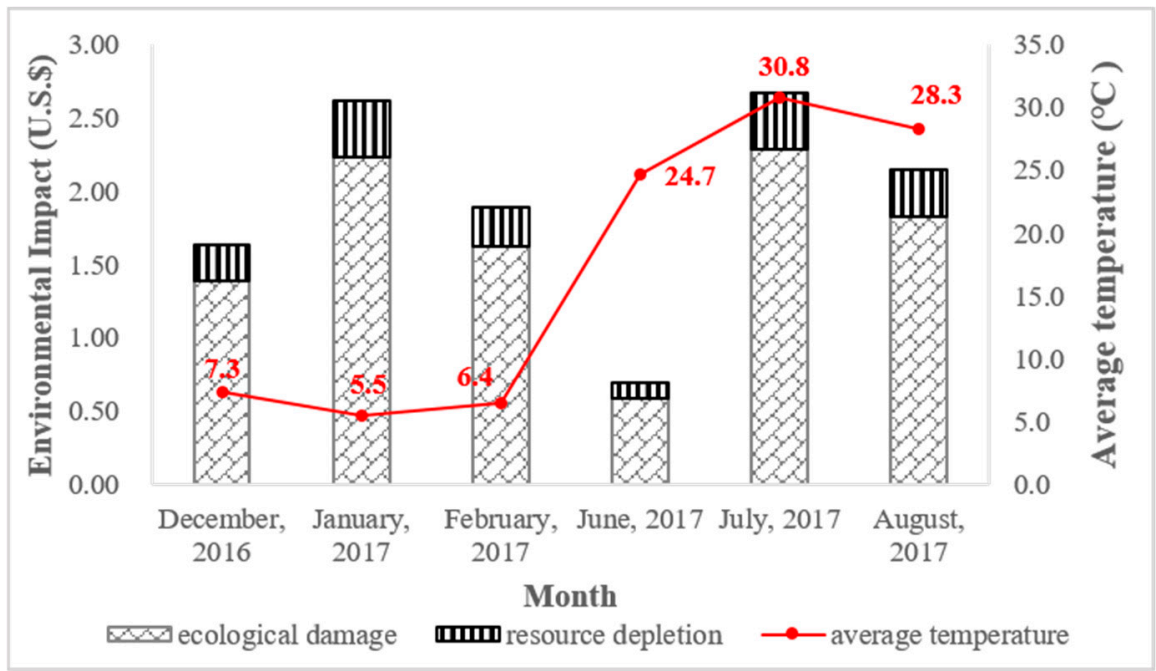

Figure 6. The monthly EI values of the IIIAC type.

\subsection{Contribution Analysis}

Based on the above results, this section analyzes the EIs of different household sizes and EIs of households with different age compositions to study their contributions and roles.

\subsubsection{A Comparison among Households with Different Sizes}

The samples are reclassified by household size, and Figure 7 depicts their average EI values. (1) The average EIs of households increased with size expansion, and the larger households caused more environmental damage. (2) The EIs due to cooling were quite dispersive, and many outliers can be observed in the figure. Even in households with the same size, the occupant usage behaviors and related EIs were quite different. This again demonstrates the diversity and importance of considering occupant behaviors, and warns that only adopting the average values as research results, which is common in many traditional studies, may be not enough and suitable. (3) Compared to the EIs due to cooling, the EIs due to heating were relatively concentrated with fewer outliers. This may because heating usage patterns were less scattered and some different usage patterns result in similar EIs. Among the four household sizes, the EIs of households with two persons and three persons were more concentrated.

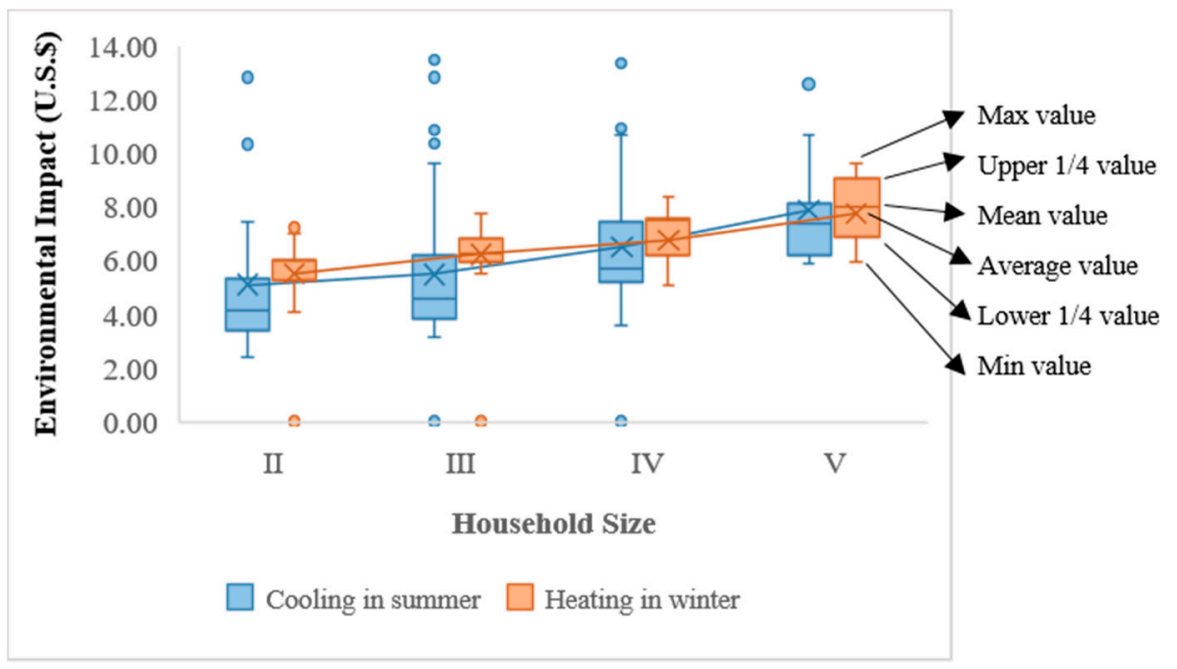

Figure 7. The annual average EI values of households with different sizes. 


\subsubsection{A Comparison among Households with Different Age Compositions}

To explore the influence of age composition, the samples were reclassified into four groups based on whether there were elderly people or children among family members: households with the elderly, households without the elderly, households with children and households without children. To exclude the influence of household size, the classification was conducted among households with the same size. The EIs due to cooling and heating were assessed separately for each group, and the average values and difference ratios are shown in Figures 8 and 9.

Figure 8 shows the following. (1) Households with elderly people had higher EIs than those without elderly people, whether in summer or in winter. Unemployed elderly people spent more time at home, and they might be more sensitive to the surrounding temperature. (2) The difference ratios changed from $0.4 \%$ to $15.4 \%$, and a larger difference occurred in type II and type IV. (3) The elderly caused more damages to satisfy their comfortable living demands, and this conclusion agrees with the prior studies [26,29].

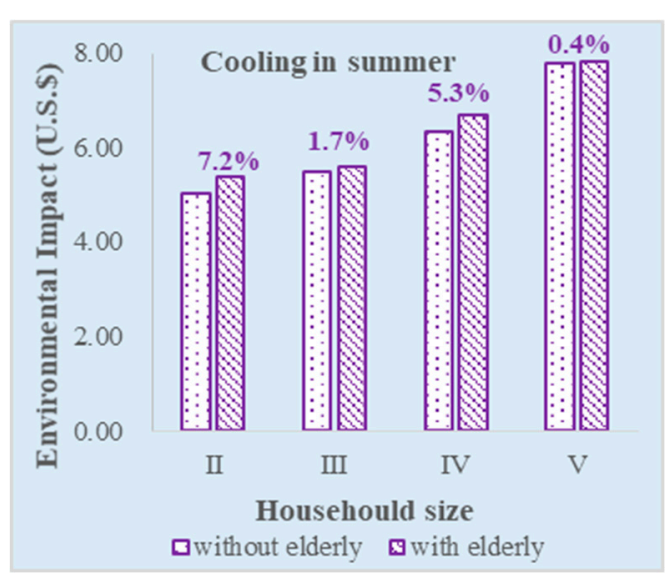

(a)

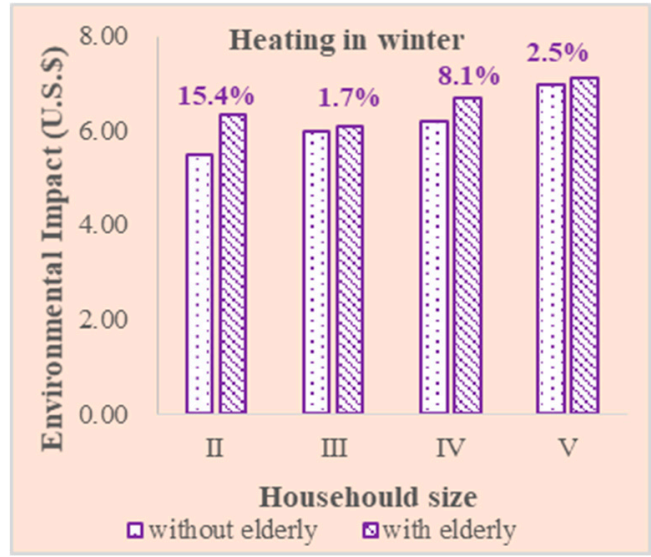

(b)

Figure 8. EIs of households with and without elderly (a) in summer and (b) in winter. Note: the difference ratios represent how much the EIs of households with elderly people were higher than the corresponding EIs of households without elderly people.

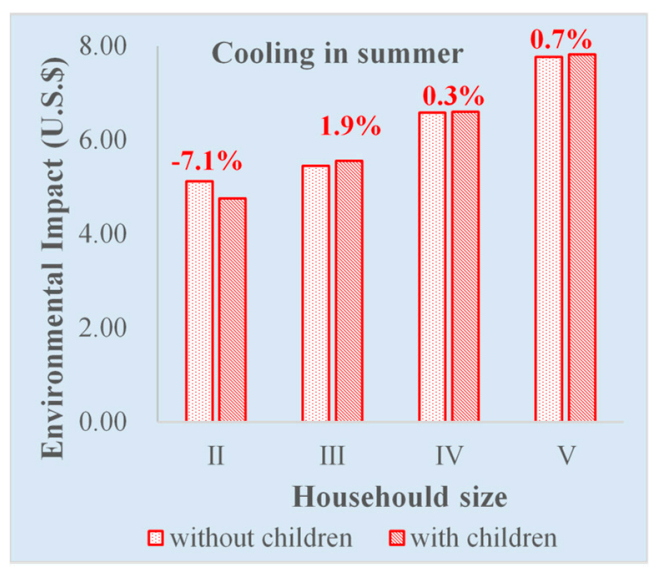

(a)

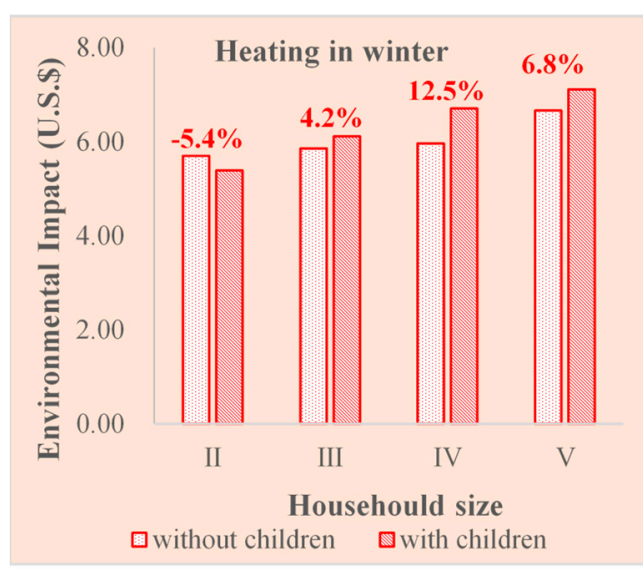

(b)

Figure 9. EIs of households with and without children (a) in summer and (b) in winter. Note: the difference ratios present how much the EIs of households with children were higher than the corresponding EIs of households without children.

Figure 9 shows the following. (1) Most households with children had higher EIs than those without children both in summer and in winter. These families tended to care more about comfortable living 
conditions and spent more time and efforts on childcare. (2) The opposite results are shown in type II households. TypeIIhouseholds with children had high possibilities of being a single parent family and suffering a heavy economic burden. They had to restrain their comfortable living behavior to save money. This may be a main reason for the abnormal negative difference ratios. (3) The difference ratios in winter were relatively larger than those in summer, which was not observed in Figure 8. The children's demand for heating was much larger than the demand for cooling.

\section{Discussion}

This study developed an integrated assessment model and compared the environmental performance of cooling and heating among different household types in China's hot summer-cold winter climate zone. The model adopted EI indicators to replace the traditional energy consumption indicator to better represent the real damage. It also took differences of basic inventory data of energy in various regions into consideration. Besides, input parameters were differentiated into sample-specific data and constant data, making it possible to just focus on household size and age composition and exclude other driving factors' influences. The model builds a better bridge between targeted behavioral driving factors and the consequential EIs.

A study was conducted in Jiangsu Province of China to demonstrate the operability of the proposed model. The EIs due to cooling and heating of nine household types were compared, and the contributions of household size and age composition were analyzed. Results were consistent with existing studies, and showed that households with larger size, children and old people tended to have higher EIs. This study could help better understand the roles of household types.

However, there are still some limitations. First, most of the input parameters were derived from a questionnaire survey. The representativeness of the samples and the authenticity of responses may influence the final results to some extent. Although some rounds of checks were conducted and a large sample was collected to make improvements, this issue cannot be totally solved. Second, input parameters were classified into sample-specific ones and constant ones in the simulations, thus the correlations between them were not considered. For example, larger households (sample-specific data) have higher possibilities of living in larger houses (constant data). This may cause some uncertainties. However, this study aims to explore the relationships between the selected driving factors and EIs, and keeping some parameters as constant values would help reach the research goal. Third, some other factors, such as the aging of air conditioners and refrigerant emissions, could also have influences on the final EIs. However, they were not involved in this study.

\section{Conclusions}

Cooling and heating in residential buildings in the hot summer-cold winter zone cause serious EIs, and occupant usage behavior plays a significant role. These behaviors are affected by many driving factors, and this study highlighted the influences of household size and age composition. An integrated assessment model was developed by combining a questionnaire survey, an energy simulation, and an environmental performance assessment. A study was conducted in Jiangsu Province of China with nearly 1800 valid samples collected. The operability of the integrated models was well testified. The EIs due to cooling and heating of nine household types, of four household sizes, and of households with different age compositions were evaluated and analyzed. Results showed that larger households, households with elderly people, and households with children would have higher EIs due to cooling and heating in Jiangsu.

This paper pays attention to household size and age composition, and future studies could address other driving factors. In addition, building design standards and occupant habits in different climate zones are quite different, thus the research conclusions could just provide a reference for buildings and residents in the hot summer-cold winter zone. The research idea and integrated model could be adopted in other climate zones. 
Supplementary Materials: The following are available online at http://www.mdpi.com/2071-1050/11/20/5724/s1.

Author Contributions: Conceptualization, X.L. and B.L.; Methodology, S.S., X.L. and B.L.; Software, S.S. and B.L.; Analysis, H.L. and J.Y.; Investigation, S.S. and X.L.; Writing-Original Draft Preparation, S.S. and X.L.; Writing-Review \& Editing, B.L., H.L. and J.Y.; Funding Acquisition, S.S. and X.L.

Funding: This study was founded by the National Key Research and Development Program of China (Grant No. 2018YFC0704400), the National Natural Science Foundation of China (Grant No. $71671042 \& 71901062$ ) and the Natural Science Foundation of Jiangsu Province, China (Grant No. BK20190377).

Conflicts of Interest: The authors declare no conflict of interest.

\section{Abbreviations}

$\begin{array}{ll}\text { BEPAS } & \text { Building Environmental Performance Analysis System } \\ \text { BEES } & \text { Building for Environmental and Economic Sustainability } \\ \text { CLCD } & \text { Chinese Life Cycle Database } \\ \text { DeST } & \text { Designer's Simulation Toolkit } \\ \text { EIs } & \text { Environmental Impacts } \\ \text { EPS } & \text { Expanded Polystyrene } \\ \text { HVAC } & \text { Heating, Ventilation, and Air Conditioning } \\ \text { MOHRUD } & \text { Ministry of Housing and Rural-Urban Development }\end{array}$

\section{References}

1. Shah, V.P.; Debella, D.C.; Ries, R.J. Life cycle assessment of residential heating and cooling systems in four regions in the United States. Energy Build. 2008, 40, 503-513. [CrossRef]

2. Tsinghua University. 2017 Annual Report on China Building Energy Efficiency; China Architecture \& Building Press: Beijing, China, 2017. (In Chinese)

3. Cai, W.G.; Ren, H.; Cao, S.P. Decomposition analysis of driving factors for building energy consumption in China. Nat. Environ. Pollut. Technol. 2014, 13,1-8.

4. Pérez-Lombard, L.; Ortiz, J.E.; Pout, C. A review on buildings energy consumption information. Energy Build. 2008, 40, 394-398. [CrossRef]

5. Hong, T.Z.; Chou, S.K.; Bong, T.Y. Building simulation: An overview of developments and information sources. Build. Environ. 2000, 35, 347-361. [CrossRef]

6. Peng, C.; Yan, D.; Wu, R.H.; Wang, C.; Zhou, X.; Jiang, Y. Quantitative description and simulation of human behavior in residential buildings. In Proceedings of Building Simulation; Tsinghua University Press: Beijing, China, 2012; pp. 85-94.

7. Wei, S.; Jones, R.; De Wilde, P. Driving factors for occupant-controlled space heating in residential buildings. Energy Build. 2014, 70, 36-44. [CrossRef]

8. Su, S.; Li, X.D.; Zhu, Y.M.; Lin, B.R. Dynamic LCA framework for environmental impact assessment of buildings. Energy Build. 2017, 149, 310-320. [CrossRef]

9. Chen, S.Q.; Yang, W.W.; Yoshino, H.; Levine, M.D.; Newhouse, K.; Hinge, A. Definition of occupant behavior in residential buildings and its application to behavior analysis in case studies. Energy Build. 2015, 104, 1-13. [CrossRef]

10. Hong, T.Z.; Taylor-Lange, S.C.; D'Oca, S.; Yan, D.; Corgnati, S.P. Advances in research and applications of energy-related occupant behavior in buildings. Energy Build. 2016, 116, 694-702. [CrossRef]

11. Li, Z.J.; Jiang, Y.; Wei, Q.P. Survey on energy consumption of air conditioning in summer in a residential building in Beijing. J. Heat. Vent. Air Cond. 2007, 37, 46-51. (In Chinese)

12. Feng, X.H.; Yan, D.; Wang, C.; Sun, H.S. A preliminary research on the derivation of typical occupant behavior based on large-scale questionnaire surveys. Energy Build. 2016, 117, 332-340. [CrossRef]

13. Delzendeh, E.; Wu, S.; Lee, A.; Zhou, Y. The impact of occupants' behaviours on building energy analysis: A research review. Renew. Sustain. Energy Rev. 2017, 80, 1061-1071. [CrossRef]

14. Hong, T.Z.; Chen, Y.X.; Belafi, Z.; D'Oca, S. Occupant behavior models: A critical review of implementation and representation approaches in building performance simulation programs. In Proceedings of Building Simulation; Tsinghua University Press: Beijing, China, 2018; pp. 1-14. 
15. Xu, L.Y.; Liu, J.J.; Pei, J.J.; Han, X. Building energy saving potential in Hot Summer and Cold Winter (HSCW) Zone, China-Influence of building energy efficiency standards and implications. Energy Policy 2013, 57, 253-262. [CrossRef]

16. Wang, Z.; Zhao, Z.; Lin, B.R.; Zhu, Y.X.; Ouyang, Q. Residential heating energy consumption modeling through a bottom-up approach for China's Hot Summer-Cold Winter climatic region. Energy Build. 2015, 109, 65-74. [CrossRef]

17. French, L.; Camilleri, M.; Isaacs, N.; Pollard, A. Temperatures and heating energy in New Zealand houses from a nationally representative study-HEEP. Energy Build. 2007, 39, 770-782. [CrossRef]

18. Andersen, R.V.; Olesen, B.W.; Toftum, J. Modelling occupants' heating set-point prefferences. In Proceedings of the 12th Conference of International Building Performance Simulation Association, Sydney, Australia, 14-16 November 2011; pp. 1451-1456.

19. Santin, O.G.; Itard, L.; Visscher, H. The effect of occupancy and building characteristics on energy use for space and water heating in Dutch residential stock. Energy Build. 2009, 41, 1223-1232. [CrossRef]

20. Gram-Hanssen, K. Residential heat comfort practices: Understanding users. Build. Res. Inf. 2010, 38, $175-186$. [CrossRef]

21. Shipworth, M.; Firth, S.K.; Gentry, M.I.; Wright, A.J.; Shipworth, D.T.; Lomas, K.J. Central heating thermostat settings and timing: Building demographics. Build. Res. Inf. 2010, 38, 50-69. [CrossRef]

22. Guerra-Santin, O.; Itard, L. Occupants' behaviour: Determinants and effects on residential heating consumption. Build. Res. Inf. 2010, 38, 318-338. [CrossRef]

23. Andersen, R.V.; Toftum, J.; Andersen, K.K.; Olesen, B.W. Survey of occupant behaviour and control of indoor environment in Danish dwellings. Energy Build. 2009, 41, 11-16. [CrossRef]

24. Steemers, K.; Yun, G.Y. Household energy consumption: A study of the role of occupants. Build. Res. Inf. 2009, 37, 625-637. [CrossRef]

25. Department of Economics and Social Affairs U.N. World Population Prospects 2015; Department of Economics and Social Affairs U.N.: New York, NY, USA, 2015.

26. Oreszczyn, T.; Hong, S.H.; Ridley, I.; Wilkinson, P. The Warm Front Study Group, Determinants of winter indoor temperatures in low income households in England. Energy Build. 2006, 38, 245-252. [CrossRef]

27. Sardianou, E. Estimating space heating determinants: An analysis of Greek households. Energy Build. 2008, 40, 1084-1093. [CrossRef]

28. Pu, Q.P.; Li, B.Z. Impact factors analysis of residential buildings' energy consumption in Huainan. In Proceedings of the IEEE International Conference on Remote Sensing, Nanjing, China, 24-26 June 2011; pp. 1278-1281.

29. Kane, T.; Firth, S.K.; Allinson, D.; Irvine, K.; Lomas, K.J. Does the Age of the Residents Influence Occupant Heating Practice in UK Domestic Buildings? In Proceedings of the East Midlands Universities Association 2010 Conference-Perspectives in Society: Health, Culture and the Environment, Leicester, UK, 14 September 2010. 8p.

30. Liao, H.; Chang, T. Space-heating and water-heating energy demands of the aged in the US. Energy Econ. 2002, 24, 267-284. [CrossRef]

31. Dixit, M.K.; Fernández-Solís, J.L.; Lavy, S.; Culp, C.H. Identification of parameters for embodied energy measurement: A literature review. Energy Build. 2010, 42, 1238-1247. [CrossRef]

32. Integrated Knowledge for our Environment (IKE). A Life-Cycle Model of Chinese Grid Power and Its Application to the Life Cycle Impact Assessment of Primary Aluminium. Available online: http://www. world-aluminium.org/publications/ (accessed on 23 May 2019).

33. Yu, X.Q.; Yan, D.; Sun, K.Y.; Hong, T.Z.; Zhu, D.D. Comparative study of the cooling energy performance of variable refrigerant flow systems and variable air volume systems in office buildings. Appl. Energy 2016, 183, 725-736. [CrossRef]

34. Roux, C.; Schalbart, P.; Peuportier, B. Accounting for temporal variation of electricity production and consumption in the LCA of an energy-efficient house. J. Clean. Prod. 2016, 113, 532-540. [CrossRef]

35. Collinge, W.O.; Rickenbacker, H.J.; Landis, A.E.; Thiel, C.L.; Bilec, M.M. Dynamic life cycle assessments of a conventional green building and a net zero energy building: Exploration of static, dynamic, attributional, and consequential electricity grid models. Environ. Sci. Technol. 2018, 52, 11429-11438. [CrossRef] 
36. Collinge, W.O.; Landis, A.E.; Jones, A.K.; Schaefer, L.A.; Bilec, M.M. Indoor environmental quality in a dynamic life cycle assessment framework for whole buildings: Focus on human health chemical impacts. Build. Environ. 2013, 62, 182-190. [CrossRef]

37. Collinge, W.O.; Landis, A.E.; Jones, A.K.; Schaefer, L.A.; Bilec, M.M. Productivity metrics in dynamic LCA for whole buildings: Using a post-occupancy evaluation of energy and indoor environmental quality tradeoffs. Build. Environ. 2014, 82, 339-348. [CrossRef]

38. Zhu, D.D.; Hong, T.Z.; Yan, D.; Wang, C. A detailed loads comparison of three building energy modeling programs: EnergyPlus, DeST and DOE-2.1E. In Proceedings of Building Simulation; Tsinghua University Press: Beijing, China, 2013; pp. 323-335.

39. de Souza, C.B. Contrasting paradigms of design thinking: The building thermal simulation tool user vs. the building designer. Autom. Constr. 2012, 22, 112-122. [CrossRef]

40. Tsinghua University, Designer's Simulation Toolkit (DEST). 2014. Available online: http://dest.tsinghua.edu. cn/ (accessed on 23 March 2018).

41. Zhang, Z.H.; Wu, X.; Yang, X.M.; Zhu, Y.M. BEPAS-A life cycle building environmental performance assessment model. Build. Environ. 2006, 41, 669-675. [CrossRef]

42. Athena Sustainable Materials Institute. Athena Impact Estimator for Buildings. Available online: http: //www.athenasmi.org/our-software-data/impact-estimator/ (accessed on 14 June 2019).

43. Building Research Establishment. Envest. Available online: http://envestv2.bre.co.uk/account.jsp (accessed on 14 June 2019).

44. Lippiatt, B.C. BEES 4.0. Building for Environmental and Economic Sustainability Technical Manual and User Guide; National Institute of Standards and Technology: Gaithersburg, MD, USA; Building and Fire Research Laboratory: Gaithersburg, MD, USA, 2007.

45. Ren, X.X.; Yan, D.; Wang, C. Air-conditioning usage conditional probability model for residential buildings. Build. Environ. 2014, 81, 172-182. [CrossRef]

46. Wang, C. Simulation Research on Occupant Energy-Related Behaviors in Building; Tsinghua University: Beijing, China, 2014. (In Chinese)

47. Yan, D.; Xia, J.J.; Tang, W.Y.; Song, F.T.; Zhang, X.L.; Jiang, Y. DeST-An integrated building simulation toolkit Part I: Fundamentals. In Proceedings of Building Simulation; Tsinghua University Press: Beijing, China, 2008; pp. 95-110.

48. DeST Development Team. Manual of DeST-h; Tsinghua University Press: Beijing, China, 2004.

49. Ministry of Housing and Urban-Rural Development of the People's Republic of China (MOHURD). GB/T 50378-2014 Assessment standard for green building; China Architecture \& Building Press: Beijing, China, 2014. (In Chinese)

50. MOHURD. GB/T 50640-2010 Evaluation Standard for Green Construction of Buildings; China Planning Press: Beijing, China, 2011. (In Chinese)

51. Li, X.D.; Su, S.; Zhang, Z.H.; Kong, X.Q. An integrated environmental and health performance quantification model for pre-occupancy phase of buildings in China. Environ. Impact Asses. 2017, 63, 1-11. [CrossRef]

52. Li, X.D.; Su, S.; Shi, J.; Zhang, Z.H. An environmental impact assessment framework and index system for the pre-use phase of buildings based on distance-to-target approach. Build. Environ. 2015, 85, 173-181. [CrossRef]

53. Su, S.; Zhu, C.; Li, X.D. A dynamic weighting system considering temporal variations using the DTT approach in LCA of buildings. J. Clean. Prod. 2019, 220, 398-407. [CrossRef]

54. Cao, X.Y.; Li, X.D.; Zhu, Y.M.; Zhang, Z.H. A comparative study of environmental performance between prefabricated and traditional residential buildings in China. J. Clean. Prod. 2015, 109, 131-143. [CrossRef]

55. Li, X.D.; Su, S.; Gao, Y.X.; Zhang, Z.H. Environmental impacts of residential buildings having differents structures. J. Tsinghua Univ. (Sci. Technol.) 2013, 9, 1255-1260. (In Chinese)

56. Su, S.; Li, X.D.; Wang, T.; Zhu, Y.M. A comparative study of environmental performance between CFST and RC columns under combinations of compression and bending. J. Clean. Prod. 2016, 137, 10-20. [CrossRef]

57. Zhu, C.; Chang, Y.; Su, S.; Li, X.D.; Zhang, Z.H. Development of qL-EIV interactive curves for comparison of the environmental performance of composite slabs and RC slabs from the perspective of mechanical features. Sci. Total Environ. 2019, 683, 508-523. [CrossRef] 
58. International Standardization Organization (ISO). ISO 14042 Environmental Management-Life Cycle Assessment-Life Cycle Impact Assessment; International Standardization Organization: Geneva, Switzerland, 2001.

59. Statistics Bureau of Jiangsu Province. 2017 Jiangsu Statistical Yearbook; Statistics Bureau of Jiangsu Province: Nanjing, China, 2017. (In Chinese)

60. Housing and Urban-Rural Construction Department of Jiangsu Province. DGJ32J 71-2014 Design Standard of Thermo-Environment and Conservation for Residential Buildings in Jiangsu Province; Phoenix Science Press: Nanjing, China, 2014. (In Chinese)

61. IKE. Chinese Life Cycle Database. (In Chinese). Available online: http://www.ike-global.com/products-2/ chinese-lca-database-clcd (accessed on 19 June 2019).

(C) 2019 by the authors. Licensee MDPI, Basel, Switzerland. This article is an open access article distributed under the terms and conditions of the Creative Commons Attribution (CC BY) license (http://creativecommons.org/licenses/by/4.0/). 